\title{
The leaky funnel model, a metaphor of the ventilation of the World Ocean as simulated in an OGCM
}

\author{
By ANNE MOUCHET ${ }^{1 *}$ and ERIC DELEERSNIJDER ${ }^{2},{ }^{1}$ Université de Liège, Astrophysics, Geophysics \\ and Oceanography Department, 17 Allée du Six-Août, 4000 Liège, Belgium; ${ }^{2}$ Université catholique de Louvain, \\ Louvain School of Engineering, Centre for Systems Engineering and Applied Mechanics (CESAME), 4 Avenue \\ Georges Lemaître, 1348 Louvain-la-Neuve, Belgium
}

(Manuscript received 11 January 2007; in final form 24 January 2008)

\begin{abstract}
ABS TR ACT
It is seen that an idealized model may suggest an appropriate scaling of the water age in the World Ocean, which is a measure of the ventilation rate. We use a 1-D advection-diffusion model in which the deep ocean is represented as a leaky funnel, allowing recirculation towards the surface. The analytical solutions to the steady-state problem are readily obtained. The three parameters of the leaky funnel model are estimated in such a way that the behaviour of the domain-averaged water age be as similar as possible to that derived from a 3-D model in a series of sensitivity runs. The agreement between both sets of mean ages is excellent, with a linear correlation coefficient very close to unity. A good agreement is also found for the age of radioactive tracers and the associated radioages. The parameters of the leaky funnel model have a clear physical meaning, that is, the order of magnitude of the horizontal velocity, the mean length of water parcel trajectories in the deep ocean, and a horizontal diffusivity scale. The values of all of them turn out to be consistent with our current knowledge of the World Ocean circulation.
\end{abstract}

\section{Introduction}

The large-scale ocean circulation exerts a strong control on the Earth climate: it plays a significant role in heat and water transport as well as in the exchange of greenhouse gases with the atmosphere. It is then of primary importance for Earth system studies to improve our understanding of the temporal and spatial scales of the global circulation and the renewal rate of ocean water masses.

The scales of interest can be derived either from field measurements of appropriate tracer concentrations or from ocean general circulation models (OGCMs) (e.g. England and Maier-Reimer, 2001). However, the intrinsic complexity of water masses circulation and the huge amount of information provided by OGCMs make it difficult to extract the most relevant information in a concise way. An illustration of the latter point is provided by model intercomparison studies: very often different behaviours are evidenced but in-depth explanations thereof are yet to be found (e.g. Broecker et al., 1999a; Archer et al., 2003; Dutay et al., 2004). Therefore there is a need for accompanying the necessary improvement and development of 3-D models with the build-up

\footnotetext{
*Corresponding author.

e-mail: a.mouchet@ulg.ac.be

DOI: $10.1111 / \mathrm{j} .1600-0870.2008 .00322 . x$
}

of elementary tools and simple experiments. Ideally such tools should provide easily dealt with mathematical formulations in order to help clearly identify the main driving processes together with their relevant spatial and temporal timescales.

In this paper, we suggest such a tool which could help in summarizing or comparing complex 3-D OGCMs results. The intent underlying such a step is to understand processes rather than to simulate nature. This approach is in line with other simple formulations already successfully applied in ocean circulation studies (e.g. Maier-Reimer, 1993; Doney and Jenkins, 1994; Huang, 1999)

A widely used simplified tool consists in the 1-D advectiondiffusion model. Analytical solutions are readily obtained from which characteristic scales may be derived. Using different assumptions (e.g. finite or infinite domain, negligible diffusion, etc.) this model may be applied to a range of situations.

Analyses of the ocean inventory of anthropogenic carbon (Gruber, 1998; Thomas and Ittekkot, 2001) or of the ventilation rate of the thermocline (Jenkins, 1998; Robbins et al., 2000) implicitly or explicitly rely on the assumption that mixing is negligible. This is equivalent to considering a purely advective transport in an infinite pipe (Hall et al., 2002). Maier-Reimer (1993) interpreted the distribution of ${ }^{14} \mathrm{C}$ versus ${ }^{39} \mathrm{Ar}$ in his 3-D model with the help of analytical solutions to the purely advective and purely diffusive problems in a 1-D infinite pipe. 
Munk (1966) inferred the deep ocean mixing rate from a vertical advection-diffusion balance model applied to a finite domain. When adjusted to density and radiocarbon data for the Pacific Ocean this model led to values of the vertical velocity and the diffusion coefficient of the order of $10^{-7}$ and $10^{-4} \mathrm{~m}^{2} \mathrm{~s}^{-1}$, respectively. Munk and Wunsch (1998) applied a modified version of this model to the global ocean and obtained results agreeing well with the previous work of Munk (1966). Munk's model was also used to understand the relationship between the distributions of ${ }^{39} \mathrm{Ar}$ and ${ }^{14} \mathrm{C}$ in the deep ocean (Broecker and Peng, 2000) or to assess the oxygen consumption rate in the deep Pacific Ocean (Craig, 1971).

A leaky pipe model was applied to study the distribution of tracers in the tropical atmosphere (Neu and Plumb, 1999). This model differs from those cited above in that the wall of the pipe is permeable, allowing for lateral (cross-flow) diffusive exchange with adjacent air masses (Plumb, 1996; Neu and Plumb, 1999). A similar model is applied in the study of the propagation of tracers along a deep western boundary current (DWBC) (Doney and Jenkins, 1994; Waugh and Hall, 2005). In that case, the DWBC is modelled as a 1-D purely advective flow exchanging material with an interior region through lateral mixing.

Despite their wide use the various versions of the 1-D model suffer from serious limitations when applied to ocean ventilation. The 1-D pipe model with pure bulk advection is often used to derive ventilation times from tracer measurements but neglecting diffusion results in a significant bias affecting ventilation times (Hall et al., 2002; Delhez et al., 2003). Technical difficulties are also inherent to any formulation. In the infinite pipe configuration it is not always possible to obtain domain-averaged quantities. Analytical solutions for the general case of radioactive tracers in the model of Munk (1966) are difficult to handle. However, the main reason why these 1-D models are not fully adequate to study the large-scale ventilation of the ocean lies in their rudimentary representation of the return flow to the ocean surface. The infinite domain version does not account for that process while the finite domain version of Munk forces the water to follow a unique track.

Water mass formation is confined within restricted areas (Broecker, 1991; Broecker et al., 1998; Talley, 1999) but this may not be the case for the upwelling of abyssal water which balances the production of deep water at high latitudes. Stommel and Arons (1960) considered a spatially uniform vertical velocity. However, recent works (Polzin et al., 1997; Kunze et al., 2006; St. Laurent and Simmons, 2006) evidenced that vertical mixing in the deep is highly heterogeneous and that the actual abyssal circulation patterns are far more complex than described in Stommel and Arons (1960). Nevertheless, the general concept of a clear separation between very localized deep water formation and widely distributed return flow has remained unchallenged until now.

Here, we suggest a simple model which allows recirculation towards the surface to occur progressively. In this model the deep ocean is represented as a leaky pipe with decreasing section, that is, a leaky funnel. Under the hypothesis of homogeneous properties across the pipe section the problem reduces to the solution of a 1-D advection-diffusion equation. With the definition of the age of a tracer as the time elapsed since it left the surface mixed layer, analytical solutions to the steady-state problem are readily obtained. Moreover domain-averaged quantities are easily derived. Though this model shares similarities with the leaky pipe of Neu and Plumb (1999), it is different in the underlying concept of a changing geometry which allow tracers to progressively leave the domain of interest.

This paper is organized as follows. After a brief review of age definitions and concepts (Section 2) we present the 1-D leaky funnel in Section 3 and derive the relevant analytical solutions. The domain-averaged ages are simple functions of two independent parameters related to the flow characteristic scales. Sensitivity studies are then performed with a 3-D OGCM. The domain-averaged ages of the water and of radioactive tracers are computed for various sets of velocities and diffusivities (Section 4). These ages are compared to those predicted by the leaky funnel in Section 5. The meaning of the characteristic scales is then discussed in Section 6.

\section{Ages}

All age definitions are based on the Consituent-oriented Age and Residence time Theory (CART) (http://www.climate.be/CART Delhez et al., 1999; Deleersnijder et al., 2001, 2002; Delhez et al., 2003). CART allows for a clear distinction to be made between the age of a water mass and the ages of the radioactive tracers carried by this water. Three different ages may hence be derived in modelling studies: the age of a radioactive tracer, the age of a conservative tracer or the water age, and eventually the classical radioage. For conservative or radioactive tracers, CART's ages are exactly equivalent to those obtained from Green's functionbased approaches (e.g. Holzer and Hall, 2000; Haine and Hall, 2002), as suggested in Delhez et al. (2003).

\subsection{Age of a radioactive tracer}

Let $C_{\lambda}(t, \mathbf{x})$ denote the concentration at time $t$ and position $\mathbf{x}=$ $(x, y, z)$ of a radioactive tracer with decay rate $\lambda$ or half-life equal to $\ln 2 \lambda^{-1}$. Then $C_{\lambda}(t, \mathbf{x})$ obeys the following transport equation

$\frac{\partial C_{\lambda}}{\partial t}=-\nabla \bullet\left(\mathbf{u} C_{\lambda}-\mathbf{K} \bullet \nabla C_{\lambda}\right)-\lambda C_{\lambda}$,

with $\mathbf{u}$ the velocity vector and $\mathbf{K}$ the diffusivity tensor which is assumed to be symmetric and positive definite (Deleersnijder et al., 2001).

Delhez et al. (1999) define the age concentration $\alpha_{\lambda}$ associated to such a tracer as the product of the concentration $C_{\lambda}(t, \mathbf{x})$ and the age $a_{\lambda}(t, \mathbf{x})$ of the radioactive tracer:

$\alpha_{\lambda}(t, \mathbf{x})=C_{\lambda}(t, \mathbf{x}) a_{\lambda}(t, \mathbf{x})$. 
Delhez et al. (1999) and Deleersnijder et al. (2001) established that $\alpha_{\lambda}(t, \mathbf{x})$ satisfies the following equation

$$
\frac{\partial \alpha_{\lambda}}{\partial t}=-\nabla \bullet\left(\mathbf{u} \alpha_{\lambda}-\mathbf{K} \bullet \nabla \alpha_{\lambda}\right)-\lambda \alpha_{\lambda}+C_{\lambda} .
$$

The last term on the right-hand side of (3) constitutes a source for $\alpha_{\lambda}$ and is associated with the ageing of the constituent (Delhez et al., 1999). The contribution of this term is fully understood by considering the transport equation for $a_{\lambda}(t, \mathbf{x})$ :

$$
\frac{\partial a_{\lambda}}{\partial t}=-\nabla \bullet\left(\mathbf{u} a_{\lambda}-\mathbf{K} \bullet \nabla a_{\lambda}\right)+2 \frac{\nabla a_{\lambda} \bullet K \bullet \nabla C_{\lambda}}{C_{\lambda}}+1 .
$$

The last term on the right-hand side of (4) corresponds to the source term in (3) and expresses the increase of age with time.

Due to the existence of non-linearities in the diffusive transport, eq. (4) differs greatly from eq. (1) and would call from a specific numerical scheme in order to solve it. On the other hand a similar numerical scheme may be used to solve (1) and (3). Therefore, the method adopted herein guarantees that subgridscale parametrizations in eqs (1) and (3) are consistent with each other (Delhez et al., 1999). Once the concentration and the age concentration are obtained, the age $a_{\lambda}$ is computed from the ratio of $\alpha_{\lambda}$ to $C_{\lambda}$.

\subsection{Water age}

The age of the water is equivalent to the age of a conservative tracer (i.e. a tracer for which $\lambda=0$ ) with appropriate boundary conditions (Delhez et al., 1999; Deleersnijder et al., 2001, 2002). With $C_{w}$ and $\alpha_{w}$ the concentration and the age concentration of this conservative tracer, respectively, the associated age is then

$a_{w}(t, \mathbf{x})=\frac{\alpha_{w}(t, \mathbf{x})}{C_{w}(t, \mathbf{x})}$.

$C_{w}$ and $\alpha_{w}$ are, respectively obtained with the help of eqs (1) and (3) in which one imposes $\lambda=0$.
Since we are to investigate ocean ventilation the source region is taken to be the ocean surface $S$. Therefore, the following boundary conditions apply on $S$

$\alpha_{w}(t, \mathbf{x})=0 \quad$ and $\quad C_{w}(t, \mathbf{x})=1 \quad$ for $\quad \mathbf{x} \in S$.

In this particular case the age concentration $\alpha_{w}$ and the concentration $C_{w}$ represent those of the surface water as defined by Deleersnijder et al. (2002). It has been shown (Deleersnijder et al., 2001, 2002) that for steady-state (or $t \rightarrow \infty$ ) the associated age $a_{w}$ tends towards the age of the water or the ventilation time, which represents the time it takes for a parcel of water to travel from the surface to the location $\mathbf{x}$. Conservative water mass tracers provide a diagnostic of the transport and have been extensively used in modelling studies (Thiele and Sarmiento, 1990; Takeoka, 1991; Haidvogel and Bryan, 1992; England, 1995; Hirst, 1999) in order to estimate oceanic ventilation timescales. As we deal with steady state the tracer age $a_{w}$ is called the water age (this tracer is sometimes referred to as the perfect age tracer, Wunsch, 2002).

\subsection{Radioage}

The classical radioage $\tau_{\lambda}$ is evaluated from the ratio of the concentration of a conservative tracer $C_{0}$ to the concentration of a radioactive tracer with $C_{0}$ and $C_{\lambda}$ subject to identical boundary conditions,

$\tau_{\lambda}(t, \mathbf{x})=\frac{1}{\lambda} \ln \frac{C_{0}(t, \mathbf{x})}{C_{\lambda}(t, \mathbf{x})}$.

Tritium ages, for example, are obtained with the help of (7) from the distributions of ${ }^{3} \mathrm{H}$ and ${ }^{3} \mathrm{He}$ (Jenkins, 1987). In that case $C_{\lambda}$ represents the concentration of ${ }^{3} \mathrm{H}$ and $C_{0}$ is the sum of ${ }^{3} \mathrm{H}$ and ${ }^{3} \mathrm{He}$ concentrations. Table 1 presents an overview of the different concepts presented in this section.

Table 1. Summary of the different variables intervening in the age computation. For each variable (column 1) a meaning or definition is given in column 2, together with the relevant equation from the main text (column 4). The third column suggests oceanographic

\begin{tabular}{|c|c|c|c|}
\hline Variable & Meaning or definition & Oceanographic example & Equation in text \\
\hline$C_{\lambda}$ & Radioactive $^{\mathrm{a}}$ tracer concentration & ${ }^{3} \mathrm{H},{ }^{14} \mathrm{C}^{\mathrm{b}}$ & (1) \\
\hline$a_{\lambda}$ & Age of the radioactive tracer & - & (4) \\
\hline$\alpha_{\lambda}$ & Age concentration, $\alpha_{\lambda}=C_{\lambda} a_{\lambda}$ & - & (3) \\
\hline$C_{0}$ & Conservative tracer concentration & $\mathrm{Na},{ }^{3} \mathrm{H}+{ }^{3} \mathrm{He},{ }^{12} \mathrm{C}^{\mathrm{b}}$. & (1) with $\lambda=0$ \\
\hline$\tau_{\lambda}$ & Radioage, $\tau_{\lambda}=\frac{1}{\lambda} \ln \frac{C_{0}}{C_{\lambda}}$ & Radiocarbon age, Tritium age... & (7) \\
\hline$C_{w}$ & Water concentration & Water & (1) with $\lambda=0$ \\
\hline$\alpha_{w}$ & Water age concentration, $\alpha_{w}=C_{w} a_{w}$ & - & (3) with $\lambda=0$ \\
\hline$a_{w}$ & Water age & $\begin{array}{l}\text { No oceanographic example, widely used in modelling } \\
\text { studies (e.g. Thiele and Sarmiento, 1990; } \\
\text { England, 1995; Deleersnijder et al., 2002) }\end{array}$ & (4) \\
\hline
\end{tabular}
examples when available

${ }^{\mathrm{a}} 1 / \lambda$ is the mean life of the radioactive tracer.

${ }^{\mathrm{b}}$ The real carbon cycle is more complex than the processes considered in this study; but the concepts of CART also apply to the radiocarbon ages as derived from field studies. 
CART formalism, which is adopted herein, is an easy way of evaluating the age of every constituent of seawater or group of constituents, including seawater itself. The ages of any number of tracers are easily computed from the outputs of a numerical model. For each tracer under consideration it is indeed sufficient to include in the model a pair of eqs (1)-(3) with the appropriate boundary conditions.

\section{The leaky funnel model}

The ocean has a fully 3-D and time-varying circulation whose complexity is hardly met by lower dimension and steady-state descriptions. However, low order representations may help to capture some essential features. According to H. Stommel (Stommel, 1958; Stommel and Arons, 1960) 'the horizontal circulation in the actual ocean may be thought to be a consequence of localized sinking and generalized upwelling' (Warren, 1981). Our model is based on this simple description.

The deep ocean is idealized as a pipe whose cross-sectional area decreases alongflow. The pipe has porous walls which allow water and tracers to irreversibly leave the domain. This loss of water or matter through leakage may be interpreted as a way of allowing recirculation towards the surface as in the real ocean. This leaky funnel is schematically depicted in Fig. 1. Subduction or entrainment of surface waters feed the leaky funnel at the opening; no water is allowed to enter the funnel at any other location.

Though sharing similarities with existing 1-D models characterized by porous walls (Doney and Jenkins, 1994; Plumb, 1996; Neu and Plumb, 1999; Waugh and Hall, 2005) our model differs from these in several aspects. None of these models considers an alongflow decrease of the cross-sectional area of the pipe; when lateral, cross-flow exchange of tracer with an external region is allowed, it is represented with the help of a mixing term. Doney and Jenkins (1994), Plumb (1996) as well as Waugh and Hall (2005) consider purely advective flow within their 1-D model.

In our model water and tracers escape the domain as they are transported downstream. Both advection and diffusion processes are considered as in Neu and Plumb (1999). As represented in Fig. 1, the cross-sectional area (or section) of the funnel $S(x)$ is a function of $x$, the downstream coordinate $(0 \leq x<\infty)$. The entrainment out of the funnel takes the form of an advective flux. There is no diffusive flux of concentrations across the funnel wall, that is,

$\left(\mathbf{K} \bullet \nabla C_{\lambda}\right) \bullet \mathbf{n}=0=\left(\mathbf{K} \bullet \nabla \alpha_{\lambda}\right) \bullet \mathbf{n}$,

where $\mathbf{n}$ is an outward unit vector normal to the external envelope of the funnel. We further assume that all variables and properties are homogeneously distributed over $S$, hence they solely depend on $x$ and $t$. Integrating eqs (1) and (3) over $S(x)$ yields a 1-D problem.

Then, the concentration $C_{\lambda}(t, x)$ and the age concentration $\alpha_{\lambda}(t, x)$ of a radioactive tracer with decay rate $\lambda$ satisfy the fol-

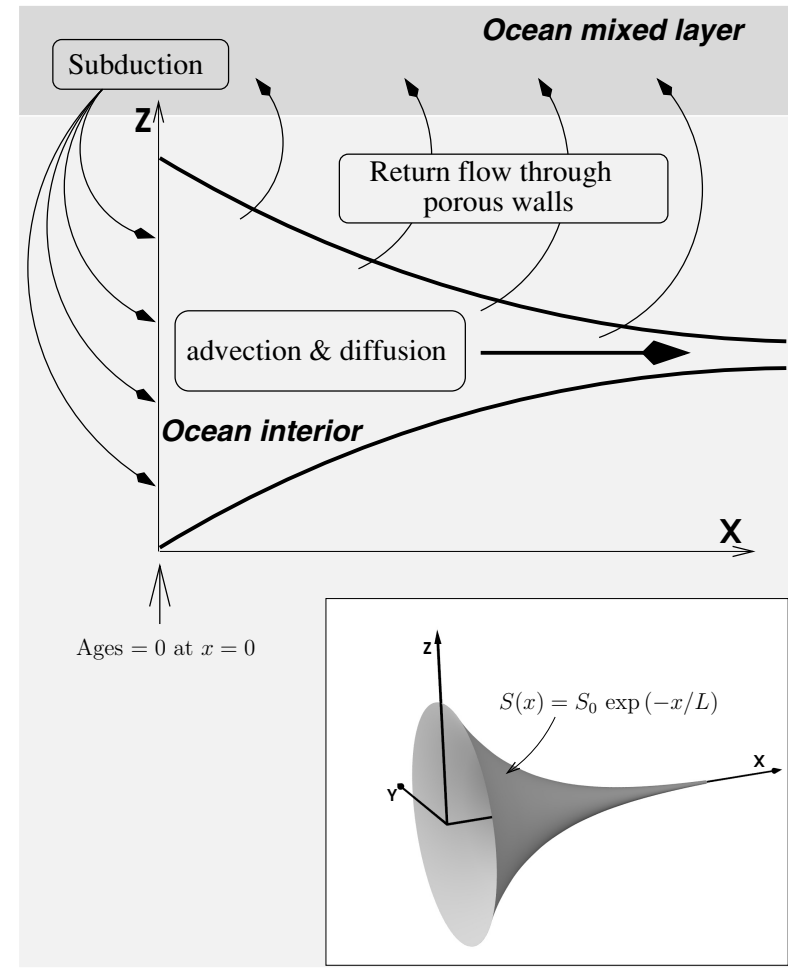

Fig. 1. Schematic representation of the leaky funnel model. A 3-D view is given in the inset while the main figure consists of a projection onto the $x-z$ plane. The leaky funnel extends from $x=0$ to $x=\infty$ with a decreasing section. The entrance of the funnel is fuelled with water subducted from the ocean surface. The porous walls allow water to escape the funnel. Advection and diffusion control the tracer transport within the funnel. At the entrance (boundary at $x=0$ ) concentrations are set to unity and ages to zero.

lowing transport equations

$$
\begin{aligned}
S \frac{\partial C_{\lambda}}{\partial t}+\frac{\partial\left(S U C_{\lambda}\right)}{\partial x}= & U C_{\lambda} \frac{\partial S}{\partial x}+\frac{\partial}{\partial x}\left(S K \frac{\partial C_{\lambda}}{\partial x}\right) \\
& -\lambda S C_{\lambda}, \\
S \frac{\partial \alpha_{\lambda}}{\partial t}+\frac{\partial\left(S U \alpha_{\lambda}\right)}{\partial x}= & U \alpha_{\lambda} \frac{\partial S}{\partial x}+\frac{\partial}{\partial x}\left(S K \frac{\partial \alpha_{\lambda}}{\partial x}\right) \\
& -\lambda S \alpha_{\lambda}+S C_{\lambda},
\end{aligned}
$$

where $U$ and $K$ represent, respectively, the velocity and the diffusivity in the funnel.

With $S$ decreasing alongflow, the first term to the right in eqs (9) and (10) represents a sink. Indeed the divergence of the flux through any section of the funnel is compensated for by the loss of water-and tracer-through the porous walls.

In order to get analytical solutions to the above equations further simplifications are necessary. First, we assume that the funnel section decreases exponentially with a constant length scale $L: S(x)=S_{0} \exp (-x / L)$. Second, we take $U$ and $K$ as positive constants and assume steady-state. Under these assumptions, the 
transport eqs (9)-(10) become

$\frac{\mathrm{d}^{2} C_{\lambda}}{\mathrm{d} x^{2}}-\frac{U^{\prime}}{K} \frac{\mathrm{d} C_{\lambda}}{\mathrm{d} x}-\frac{\lambda}{K} C_{\lambda}=0$

$\frac{\mathrm{d}^{2} \alpha_{\lambda}}{\mathrm{d} x^{2}}-\frac{U^{\prime}}{K} \frac{\mathrm{d} \alpha_{\lambda}}{\mathrm{d} x}-\frac{\lambda}{K} \alpha_{\lambda}=-\frac{1}{K} C_{\lambda}$

The modified velocity $U^{\prime}=U+K / L$ arises from the varying section $S(x)$ in the diffusive terms of (9) and (10). It is readily seen that the set of eqs (11) and (12) is equivalent to that obtained for the 1-D advection-diffusion problem in a constant-section pipe with constant velocity $U^{\prime}$ and diffusivity $K$.

At this stage it is useful to introduce the following dimensionless numbers

$P e=\frac{U L}{K} \quad$ Peclet number,

$J e=\frac{U^{2}}{K \lambda} \quad$ Jenkins number.

The Jenkins number ${ }^{1} J e$ is equivalent to a Peclet number in which the length scale would be $U \lambda^{-1}$ (Jenkins, 1987). This length scale measures the distance travelled by the radioactive tracer during its mean lifetime in the case of a purely advective flow. In addition, we define the modified Jenkins number based on the modified velocity $U^{\prime}$ :

$J e^{\prime}=\frac{\left(U^{\prime}\right)^{2}}{K \lambda}=J e\left(\frac{1+P e}{P e}\right)^{2}$.

We then apply the boundary conditions equivalent to a zero age at the entrance of the funnel, $x=0$, as defined in (6), that is,

$C_{\lambda}(x=0)=1$,

$\alpha_{\lambda}(x=0)=0$.

For $x \rightarrow \infty$ we impose that the tracer concentration is bounded and that the age concentration does not increase exponentially.

Under these conditions the solutions to (11) and (12) read

$C_{\lambda}(x)=\exp \left[-\frac{U^{\prime} x}{2 K}\left(\sqrt{1+\frac{4}{J e^{\prime}}}-1\right)\right]$

$\alpha_{\lambda}(x)=\frac{x}{U^{\prime} \sqrt{1+\frac{4}{J e^{\prime}}}} \exp \left[-\frac{U^{\prime} x}{2 K}\left(\sqrt{1+\frac{4}{J e^{\prime}}}-1\right)\right]$

and the age of a radioactive tracer is

$a_{\lambda}(x)=\frac{\alpha_{\lambda}(x)}{C_{\lambda}(x)}=\frac{x}{U^{\prime}} \sqrt{\frac{J e^{\prime}}{4+J e^{\prime}}}$.

${ }^{1}$ We suggest this number be known as the 'Jenkins number' because, to the best of our knowledge, it is William Jenkins who first introduced it in ocean ventilation rate studies (e.g. Jenkins, 1987).
The age of the water or a passive tracer is obtained by taking the limit $\lambda \rightarrow 0$, that is,

$C_{w}(x)=\lim _{\lambda \rightarrow 0} C_{\lambda}(x)=1$,

$\alpha_{w}(x)=\lim _{\lambda \rightarrow 0} \alpha_{\lambda}(x)=\frac{x}{U^{\prime}}$,

implying that

$a_{w}(x)=\frac{x}{U^{\prime}}=\frac{x}{U} \frac{P e}{1+P e}$.

The radioage is also easily derived

$\tau_{\lambda}(x)=\frac{-1}{\lambda} \ln \left(\frac{C_{\lambda}(x)}{C_{w}(x)}\right)=\frac{x}{U^{\prime}} \frac{2 \sqrt{J e^{\prime}}}{\sqrt{4+J e^{\prime}}+\sqrt{J e^{\prime}}}$.

The funnel domain is infinite but its volume is finite. The latter is readily seen to be

$\Omega=\int_{0}^{\infty} S(x) \mathrm{d} x=S_{0} L$.

Hence it is possible to derive domain-averaged quantities, which we define as

$\langle y\rangle=\Omega^{-1} \int_{0}^{\infty} y(x) S(x) \mathrm{d} x$.

Then the domain-averaged ages read

$\left\langle a_{w}\right\rangle=\frac{L}{U} \frac{P e}{1+P e}$,

$\left\langle\tau_{\lambda}\right\rangle=\left\langle a_{w}\right\rangle \frac{2 \sqrt{J e^{\prime}}}{\sqrt{4+J e^{\prime}}+\sqrt{J e^{\prime}}}$,

$\left\langle a_{\lambda}\right\rangle=\left\langle a_{w}\right\rangle \sqrt{\frac{J e^{\prime}}{4+J e^{\prime}}}$.

The domain-averaged age of water $\left\langle a_{w}\right\rangle$ depends on the Peclet number and scales as $A_{0}=L / U$, which is an advective timescale. Equation (21) may also be written as

$\frac{1}{\left\langle a_{w}\right\rangle}=\frac{K}{L^{2}}+\frac{U}{L}=\frac{1}{A_{D}}+\frac{1}{A_{0}}$

in which $A_{D}=L^{2} / K$ represents a characteristic timescale for diffusion.

The relative magnitude of the terms in (24) determines which process (advection or diffusion) controls the flow timescale. The boundary between the two regimes is clearly delineated by $P e$ and eq. (21) logically exhibits the following asymptotic behaviour

$\left\langle a_{w}\right\rangle \sim A_{0} P e=A_{D}$ for $P e \rightarrow 0$,

$\left\langle a_{w}\right\rangle \sim A_{0}\left(1-\frac{1}{P e}\right)=A_{0}\left(1-\frac{A_{0}}{A_{D}}\right)$ for $P e \rightarrow \infty$.

From (22) and (23) it can be seen that the age of a radioactive tracer $a_{\lambda}$ and the radioage $\tau_{\lambda}$ both underestimate the water age and that the bias is a function of $\lambda$ (Delhez et al., 2003). These 
equations admit the following asymptotic expansions

$\frac{\left\langle a_{\lambda}\right\rangle}{\left\langle a_{w}\right\rangle} \sim 1-\frac{2}{J e^{\prime}}$ for $J e^{\prime} \rightarrow \infty$,
$\frac{\left\langle\tau_{\lambda}\right\rangle}{\left\langle a_{w}\right\rangle} \sim 1-\frac{1}{J e^{\prime}}$ for $J e^{\prime} \rightarrow \infty$,

and

$\frac{\left\langle a_{\lambda}\right\rangle}{\left\langle a_{w}\right\rangle} \sim \frac{J e^{\prime 1 / 2}}{2}$ for $J e^{\prime} \rightarrow 0$,

$\frac{\left\langle\tau_{\lambda}\right\rangle}{\left\langle a_{w}\right\rangle} \sim J e^{\prime 1 / 2}$ for $J e^{\prime} \rightarrow 0$.

These asymptotic expressions are consistent with those of Delhez et al. (2003). At small $\lambda$ (high $J e^{\prime}$ ) the age bias is a linear function of the decay rate. On the other hand, for a large decay rate both the radioage $\tau_{\lambda}$ and the radioactive tracer age $a_{\lambda}$ tend towards zero as $\lambda^{-1 / 2}$.

The parameters of the leaky funnel $(L, U, K)$ are to be determined in such a way that the behaviour of the mean age predicted by this simple model be as close as possible to that computed by an OGCM. This is explained below.

\section{3-D OGCM experiments}

The leaky funnel concept could be tested against field data (e.g. ${ }^{14} \mathrm{C}$ ) but this would call for complex boundary condition formulations at the surface which are not easily dealt with analytically. However, our aim is to provide a tool which could help in summarizing or comparing complex 3-D OGCMs results. We henceforth evaluate the performance of the leaky funnel against results from a 3-D ocean model. This approach is in line with other simple formulations already successfully applied in ocean circulation studies (e.g. Maier-Reimer, 1993; Huang, 1999).

\subsection{3-D model description}

We take the annual mean circulation from the Louvain-la-Neuve OGCM (Deleersnijder and Campin, 1995; Campin and Goosse, 1999). The latter is a primitive-equation, free-surface OGCM resting on the usual set of assumptions, that is, the hydrostatic equilibrium and the Boussinesq approximation. The horizontal resolution is $3^{\circ} \times 3^{\circ}$. The so-called ' $\mathrm{z}$-coordinate' underlies a vertical discretization with 15 levels ranging in thickness from $20 \mathrm{~m}$ at the surface to $700 \mathrm{~m}$ in the deep ocean. A realistic bathymetry is used. The parametrization of vertical mixing is based on the Pacanowski and Philander (1981) formulation. Wherever the vertical density profile is unstable, the vertical diffusivity (Marotzke, 1991) is increased to $10 \mathrm{~m}^{2} \mathrm{~s}^{-1}$. The parametrization of dense water flow down topographic features of Campin and Goosse (1999) is applied in the model. The experimental set up for the OGCM circulation corresponds to the control run described in Campin et al. (1999). The OGCM was assessed against the global distributions of temperatures, salinities as well as the estimated values of water transport in different
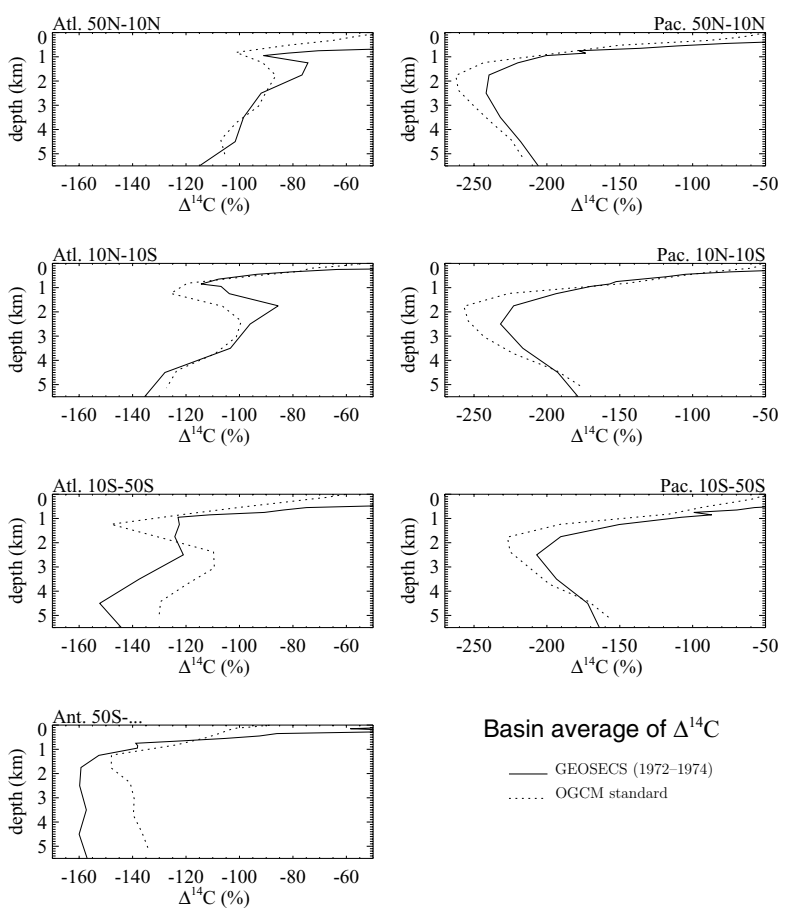

Fig. 2. Mean $\Delta^{14} \mathrm{C}$ vertical profiles in several oceanic basins from GEOSECS data (solid) and from the OGCM standard version (dotted). The values in the North, Equatorial and Southern Atlantic and Pacific Oceans are reproduced, respectively, in the upper left and right three panels, with the bottom panel representing the Southern Ocean (south of $50^{\circ} \mathrm{S}$ ). The pre-industrial OGCM $\Delta^{14} \mathrm{C}$ is computed with the simplified method of Toggweiler et al. (1989). The discrepancy between model and data in the upper ocean partly results from the penetration of bomb ${ }^{14} \mathrm{C}$ that is not considered in this model experiment.

locations (North Atlantic, Drake passage...). Without any further tuning we then simulate the $\Delta^{14} \mathrm{C}$ distribution following the approach of Toggweiler et al. (1989). The circulation reasonably reproduces the pre-bomb $\Delta{ }^{14} \mathrm{C}$ distribution in the deep ocean (Fig. 2).

The model simulates the distribution of the concentrations and age concentrations of water together with those of three radioactive tracers: ${ }^{14} \mathrm{C}\left(\lambda=1.2 \times 10^{-4} \mathrm{yr}^{-1}\right),{ }^{39} \mathrm{Ar}(\lambda=$ $\left.2.5 \times 10^{-3} \mathrm{yr}^{-1}\right)$ and ${ }^{3} \mathrm{H}\left(\lambda=5.6 \times 10^{-2} \mathrm{yr}^{-1}\right)$. These modelled radioactive tracers are idealized versions of the natural tracers. For example, we do not take into account the complex boundary conditions arising from the heterogeneity of air-sea fluxes in the real ocean, nor do we consider the dependency of ${ }^{14} \mathrm{C}$ air-sea fluxes on carbonate chemistry.

The boundary conditions at the surface for $\alpha_{\lambda}, C_{\lambda}, a_{w}$ and $C_{w}$ correspond to a restoring of surface values to fixed values (concentrations $=1$, ages $=0$ ) using a very small restoring time constant $(\simeq 1 / 3 \mathrm{~d})$. On the other hand, advective and diffusive fluxes across the ocean floor and lateral boundaries are set to zero. 


\subsection{Experimental setup}

The leaky funnel yields an expression of the domain-averaged water age containing the parameters $A_{0}$ and $P e$ (Eq. 23). As will be seen later, the 3 -D numerics calls for an additional parameter to be determined. In order to estimate these parameters from the domain-averaged 3-D OGCM water age we need several solutions to the OGCM transport process. For this purpose we performed a number of numerical experiments in which the velocity and the diffusivity tensor of the standard run, hereafter denoted $\mathbf{u}_{S}$ and $\mathbf{K}_{S}$, were homogeneously multiplied by constant factors. These modifications were achieved by running the tracer model off-line, which solely affects the distribution of the nondynamically active tracers.

Artificial modification of the velocity field in a 3-D transport model has previously been performed in ventilation studies (e.g. Heinze et al., 1991). While such artificial changes are not the consequence of any physical mechanism they help answering the not so trivial question "what tracer distributions, what timescales, would be relevant if the circulation was more sluggish or more rapid?'.

It should be stressed that the modified velocities and diffusivities applied in the off-line tracer model do not correspond to dynamically consistent states. Only the reference state is dynamically consistent (momentum and buoyancy equations) and in agreement with the boundary conditions at the ocean surface. The other states may be viewed as artefacts that are necessary for the values $P e$ and $A_{0}$ to be determined. Modifying independently the velocity and the diffusivity contradicts the momentum equation and the dynamical balances of the model. However it is easily seen that the continuity equation remains verified. Hence mass is conserved for all of the sensitivity experiments. The condition of no flux through ocean boundaries and the finite volume method which is used for discretizing the transport equations further guarantee that the system is mass-conserving. Nevertheless, no attempt is made here to generate dynamically consistent states from the OGCM, since the objective of the present study solely consists in establishing the order of magnitude of the timescales related to the transport processes.

With $M$ the total number of experiments, the velocity and explicit diffusivity for experiment $i(i=1, \ldots, M)$ are then

$\mathbf{u}_{i}=\gamma_{i} \mathbf{u}_{S} \quad$ and $\quad \mathbf{K}_{i}=\beta_{i} \mathbf{K}_{S}$.

In other words, the transport operator in experiment $i$ is of the form

$\nabla \bullet\left(\mathbf{u}_{i} \xi-\mathbf{K}_{i} \bullet \nabla \xi\right)=\nabla \bullet\left(\gamma_{i} \mathbf{u}_{S} \xi-\beta_{i} \mathbf{K}_{\mathrm{S}} \bullet \nabla \xi\right)$

where $\xi \in\left\{C_{w}, \alpha_{w}, C_{\lambda}, \alpha_{\lambda}\right\} . M=26$ experiments are performed with $\gamma_{i}$ comprised between 0.125 and 2.0 and $\beta_{i}$ between 1 and 6 (Table 2). The model is integrated over several thousand years (up to $30 \times 10^{3} \mathrm{yr}$ for small $\gamma_{i}$ ) in order to achieve a steady-state of the tracer concentration and age concentration fields.
Let $U_{S}$ and $K_{S}$ denote the values of velocity and diffusivity in the leaky funnel corresponding to the flow conditions of the standard run of the OGCM. The velocity corresponding to experiment $i$ is then

$U_{i}=\gamma_{i} U_{S}$

However, the associated diffusivity is not $\beta_{i} K_{S}$, for the impact of numerical diffusion must be taken into account. As the latter is proportional to the velocity (Roache, 1972), the leaky funnel diffusivity actually is

$K_{i}=\beta_{i} K_{S}^{E}+\gamma_{i} K_{S}^{N}$

where $K_{S}^{E}$ and $K_{S}^{N}$ represent the contributions from explicit and numerical diffusivities, associated with the standard version of the 3-D transport model. Obviously, the total diffusivity of the leaky funnel model that is associated with the 3-D model standard run is $K_{S}=K_{S}^{E}+K_{S}^{N}$.

It follows that the global Peclet number associated with experiment $i$ is given by

$\frac{1}{P e_{i}}=\frac{\beta_{i} K_{S}^{E}+\gamma_{i} K_{S}^{N}}{\gamma_{i} U_{S} L}=\frac{\beta_{i}}{\gamma_{i}} \frac{1}{P e^{E}}+\frac{1}{P e^{N}}$,

where $P e^{E}=U_{S} L / K_{S}^{E}$ and $P e^{N}=U_{S} L / K_{S}^{N}$ represent the Peclet numbers associated with the explicit and numerical diffusion, respectively.

If the leaky funnel model describes properly the ventilation of the deep ocean in the 3-D model, then the 3-D domain-averaged water ages $\left(\left\langle a_{w}\right\rangle\right)$ from the $M$ experiments would follow (21) with $U$ and $K$ replaced by expressions (27) and (28). Hence the predicted domain-averaged water age for experiment $i,\left\langle\hat{a}_{w}\right\rangle_{i}$, is given by

$$
\left\langle\hat{a}_{w}\right\rangle_{i}=\frac{L}{U_{i}} \frac{P e_{i}}{1+P e_{i}}=\frac{A_{0}}{\gamma_{i}} \frac{1}{1+\frac{\beta_{i}}{\gamma_{i}} \frac{1}{P e^{E}}+\frac{1}{P e^{N}}} .
$$

The predicted ages, that is, the ages derived from the leaky funnel model, depend on three unknown parameters $\left(A_{0}, P e^{E}\right.$ and $P e^{N}$ ), the dependencies on $P e^{E}$ and $P e^{N}$ being non-linear. As the number of experiments $M$ is much larger than three, the system defined by (30) is overdetermined. The values of the three unknown parameters are determined by an optimization procedure. They are adjusted so as to achieve the minimum of the quadratic expression

$\sum_{i=1}^{M}\left(\left\langle\hat{a}_{w}\right\rangle_{i}-\left\langle a_{w}\right\rangle_{i}\right)^{2}$,

where $\left\langle a_{w}\right\rangle_{i}$ is the OGCM domain-averaged water age obtained with experiment $i$. The Levenberg-Marquardt non-linear leastsquares algorithm (Press et al., 1988) is used to determine $A_{0}$, $P e^{E}$ and $P e^{N}$ from the water ages obtained with the 3-D model (Table 2). 
Table 2. Domain-averaged ages obtained for the $M=26$ experiments with the 3-D OGCM: water age (column 4) followed by the radioactive age and the radioage of ${ }^{14} \mathrm{C}$ (columns $5 \& 6$ ), ${ }^{39} \mathrm{Ar}$ (columns $7 \& 8$ ) and ${ }^{3} \mathrm{H}$ (columns $9 \& 10$ ). The values for $\gamma_{i}$ and $\beta_{i}$ corresponding to each experiment $i$ are given in the second and third columns

\begin{tabular}{|c|c|c|c|c|c|c|c|c|c|}
\hline \multirow[b]{2}{*}{$i$} & \multirow[b]{2}{*}{$\gamma_{i}$} & \multirow[b]{2}{*}{$\beta_{i}$} & \multirow{2}{*}{$\begin{array}{c}\text { Water } \\
\left\langle a_{w}\right\rangle_{i} \\
(\mathrm{yr})\end{array}$} & \multicolumn{2}{|c|}{${ }^{14} \mathrm{C}$} & \multicolumn{2}{|c|}{${ }^{39} \mathrm{Ar}$} & \multicolumn{2}{|c|}{${ }^{3} \mathrm{H}$} \\
\hline & & & & $\begin{array}{c}\left\langle\tau_{\lambda}\right\rangle_{i} \\
(\mathrm{yr})\end{array}$ & $\begin{array}{c}\left\langle a_{\lambda}\right\rangle_{i} \\
(\mathrm{yr})\end{array}$ & $\begin{array}{c}\left\langle\tau_{\lambda}\right\rangle_{i} \\
(\mathrm{yr})\end{array}$ & $\begin{array}{c}\left\langle a_{\lambda}\right\rangle_{i} \\
(\mathrm{yr})\end{array}$ & $\begin{array}{c}\left\langle\tau_{\lambda}\right\rangle_{i} \\
(\mathrm{yr})\end{array}$ & $\begin{array}{c}\left\langle a_{\lambda}\right\rangle_{i} \\
(\mathrm{yr})\end{array}$ \\
\hline 1 & 2 & 1 & 412.83 & 392.64 & 402.30 & 223.86 & 292.04 & 54.21 & 78.09 \\
\hline 2 & 1 & 1 & 763.71 & 692.73 & 726.81 & 304.63 & 443.53 & 76.65 & 105.57 \\
\hline 3 & $1 / 2$ & 1 & 1355.90 & 1139.32 & 1240.81 & 386.01 & 624.54 & 73.05 & 135.38 \\
\hline 4 & $1 / 3$ & 1 & 1832.97 & 1460.61 & 1632.16 & 429.48 & 737.07 & 81.96 & 152.80 \\
\hline 5 & $1 / 4$ & 1 & 2230.32 & 1698.62 & 1938.20 & 457.58 & 814.33 & 113.88 & 164.40 \\
\hline 6 & $1 / 5$ & 1 & 2561.77 & 1883.25 & 2183.78 & 477.39 & 871.09 & 74.37 & 172.46 \\
\hline 7 & $1 / 6$ & 1 & 2831.90 & 2028.70 & 2381.51 & 491.92 & 913.87 & 79.49 & 177.97 \\
\hline 8 & $1 / 7$ & 1 & 3071.00 & 2147.31 & 2548.51 & 503.22 & 948.04 & 75.76 & 182.14 \\
\hline 9 & $1 / 8$ & 1 & 3268.69 & 2244.41 & 2687.65 & 511.91 & 975.42 & 77.36 & 185.42 \\
\hline 10 & 2 & 2 & 395.72 & 375.77 & 385.34 & 209.91 & 277.02 & 44.77 & 81.09 \\
\hline 11 & 1 & 2 & 698.63 & 635.61 & 665.92 & 278.48 & 407.77 & 55.29 & 104.48 \\
\hline 12 & $1 / 2$ & 2 & 1143.68 & 981.10 & 1057.58 & 340.74 & 550.11 & 65.44 & 125.00 \\
\hline 13 & $1 / 3$ & 2 & 1455.77 & 1202.98 & 1320.16 & 370.26 & 628.82 & 61.55 & 135.20 \\
\hline 14 & $1 / 4$ & 2 & 1685.30 & 1354.90 & 1506.09 & 387.14 & 677.95 & 61.89 & 140.88 \\
\hline 15 & $1 / 5$ & 2 & 1860.32 & 1465.71 & 1644.71 & 398.20 & 711.61 & 62.76 & 144.69 \\
\hline 16 & $1 / 6$ & 2 & 1995.64 & 1548.62 & 1750.22 & 405.98 & 735.76 & 64.99 & 147.54 \\
\hline 17 & $1 / 7$ & 2 & 2106.54 & 1614.38 & 1835.21 & 411.92 & 754.38 & 64.13 & 149.64 \\
\hline 18 & $1 / 8$ & 2 & 2197.14 & 1666.99 & 1903.98 & 416.55 & 768.98 & 63.75 & 151.19 \\
\hline 19 & 2 & 4 & 360.60 & 343.08 & 351.57 & 192.77 & 254.29 & 37.57 & 75.88 \\
\hline 20 & 1 & 4 & 588.32 & 541.89 & 564.34 & 247.39 & 357.62 & 44.45 & 91.64 \\
\hline 21 & $1 / 2$ & 4 & 864.73 & 767.47 & 813.83 & 289.36 & 455.01 & 48.53 & 104.46 \\
\hline 22 & $1 / 3$ & 4 & 1026.21 & 891.97 & 955.45 & 306.14 & 501.44 & 50.33 & 110.30 \\
\hline 23 & $1 / 4$ & 4 & 1202.26 & 1021.67 & 1106.38 & 320.65 & 545.36 & 52.34 & 115.47 \\
\hline 24 & 2 & 6 & 329.23 & 314.31 & 321.59 & 180.38 & 236.00 & 36.97 & 70.55 \\
\hline 25 & 1 & 6 & 506.79 & 471.81 & 488.81 & 225.71 & 320.67 & 39.98 & 82.88 \\
\hline 26 & $1 / 2$ & 6 & 695.85 & 631.30 & 662.37 & 257.10 & 392.88 & 43.02 & 92.15 \\
\hline
\end{tabular}

\section{Results}

The least-squares fit of eq. (30) to the $M$ domain-averaged water ages from the 3-D model leads to the estimates of $A_{0}, P e^{E}$ and $P e^{N}$ given in Table 3. With these values one may now compute the predicted (leaky funnel) ages corresponding to each experiment. The predicted water ages are given by (30) while the predicted radioages and radioactive tracer ages are obtained

Table 3. Parameters of the leaky funnel model as obtained from a least squares fit to the 3 -D model results (domain-averaged water ages for all experiments). The last column gives the Peclet number computed from eq. (29) with $\beta_{i}=\gamma_{i}=1$

\begin{tabular}{cccc}
\hline$A_{0}$ & $P e^{E}$ & $P e^{N}$ & $P e$ \\
\hline $1010.36 \mathrm{yr}$ & 6.41 & 6.98 & 3.34 \\
\hline
\end{tabular}

from

$\left\langle\hat{\tau}_{\lambda}\right\rangle_{i}=\left\langle\hat{a}_{w}\right\rangle_{i} \frac{2 \sqrt{J e_{i}^{\prime}}}{\sqrt{4+J e_{i}^{\prime}}+\sqrt{J e_{i}^{\prime}}}$,

$\left\langle\hat{a}_{\lambda}\right\rangle_{i}=\left\langle\hat{a}_{w}\right\rangle_{i} \frac{\sqrt{J e_{i}^{\prime}}}{\sqrt{4+J e_{i}^{\prime}}}$.

which derive from (22) and (23). The modified Jenkins number $J e_{i}^{\prime}$ in the above expressions is

$J e_{i}^{\prime}=\frac{1}{\lambda} \frac{\gamma_{i} P e_{i}}{A_{0}}\left(\frac{1+P e_{i}}{P e_{i}}\right)^{2}$,

where $P e_{i}$ is given by eq. (29). Table 4 lists the leaky funnel and OGCM domain-averaged ages for the standard case $\left(\gamma_{i}=1\right.$ and $\left.\beta_{i}=1\right)$. The leaky funnel ages are presented versus OGCM ages in Figs. 3 and 4. The domain-averaged ages predicted by the leaky funnel and those obtained from the 3-D model are in excellent agreement. The linear correlation coefficients (column 4 , Table 4) for $\left\langle a_{w}\right\rangle$ and $\left\langle a_{1{ }_{14} \mathrm{C}}\right\rangle$ are very close to 1 and the 
Table 4. Assessment of the leaky funnel domain-averaged ages for the four tracers considered. The ages for the standard 3-D run are given in column 2. With $\gamma_{i}=1$ and $\beta_{i}=1$ we obtain the leaky funnel ages in column 3 from eqs (30), (31)-(32), expressions (29) and (33) and the values in Table 3. Column 4 contains the linear correlation coefficient $r$ between leaky funnel (1-D) and 3-D model domain-averaged ages. The rms difference between leaky funnel and 3-D model ages $\zeta$ is given in column 5

\begin{tabular}{|c|c|c|c|c|}
\hline \multicolumn{5}{|c|}{$\gamma_{i}=1, \quad \beta_{i}=1$} \\
\hline$\left\langle a_{w}\right\rangle$ & $763.71 \mathrm{yr}$ & $777.72 \mathrm{yr}$ & 0.9998 & $40.86 \mathrm{yr}$ \\
\hline$\left\langle\tau_{14} \mathrm{C}\right\rangle$ & $726.81 \mathrm{yr}$ & $761.56 \mathrm{yr}$ & 0.9989 & $65.69 \mathrm{yr}$ \\
\hline$\left\langle a_{14} \mathrm{C}\right\rangle$ & $692.73 \mathrm{yr}$ & $746.06 \mathrm{yr}$ & 0.9969 & $92.03 \mathrm{yr}$ \\
\hline$\left\langle\tau_{39} \mathrm{Ar}\right\rangle$ & $443.53 \mathrm{yr}$ & $582.45 \mathrm{yr}$ & 0.9867 & $142.58 \mathrm{yr}$ \\
\hline$\left\langle a_{39}{ }_{\mathrm{Ar}}\right\rangle$ & $304.63 \mathrm{yr}$ & $465.55 \mathrm{yr}$ & 0.9765 & $145.49 \mathrm{yr}$ \\
\hline$\left\langle\tau_{3_{H}}\right\rangle$ & $105.57 \mathrm{yr}$ & $209.86 \mathrm{yr}$ & 0.9479 & $82.27 \mathrm{yr}$ \\
\hline$\left\langle a_{3} \mathrm{H}\right\rangle$ & $76.65 \mathrm{yr}$ & $121.29 \mathrm{yr}$ & 0.8957 & $51.56 \mathrm{yr}$ \\
\hline
\end{tabular}

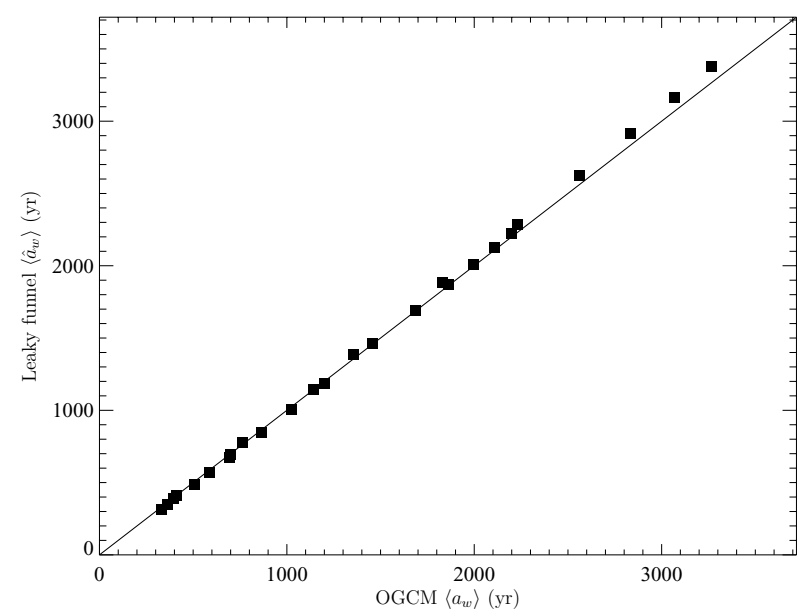

Fig. 3. Scatter plot of the predicted domain-averaged water ages versus those computed from the 3-D model. The leaky funnel ages are computed by means of eq. (30) and the parameters in Table 3 . The linear correlation coefficient is equal to 0.9998 and the rms difference $40.87 \mathrm{yr}$ (Table 4).

corresponding rms differences (column 5, Table 4) are relatively small.

It should be noted that radioages are not completely independent from the water ages. Indeed, they derive from the same advection-diffusion Green's function (e.g. Haine and Hall, 2002; Delhez et al., 2003). However, the parameters of the funnel were estimated with the help of the domain-averaged water ages. Non-linearities arising from cross-products result in additional contributions intervening in the domain-averaged radioages and radioactive tracer ages. Hence the latter provide supplementary information and additional means for assessing the quality of the fit.
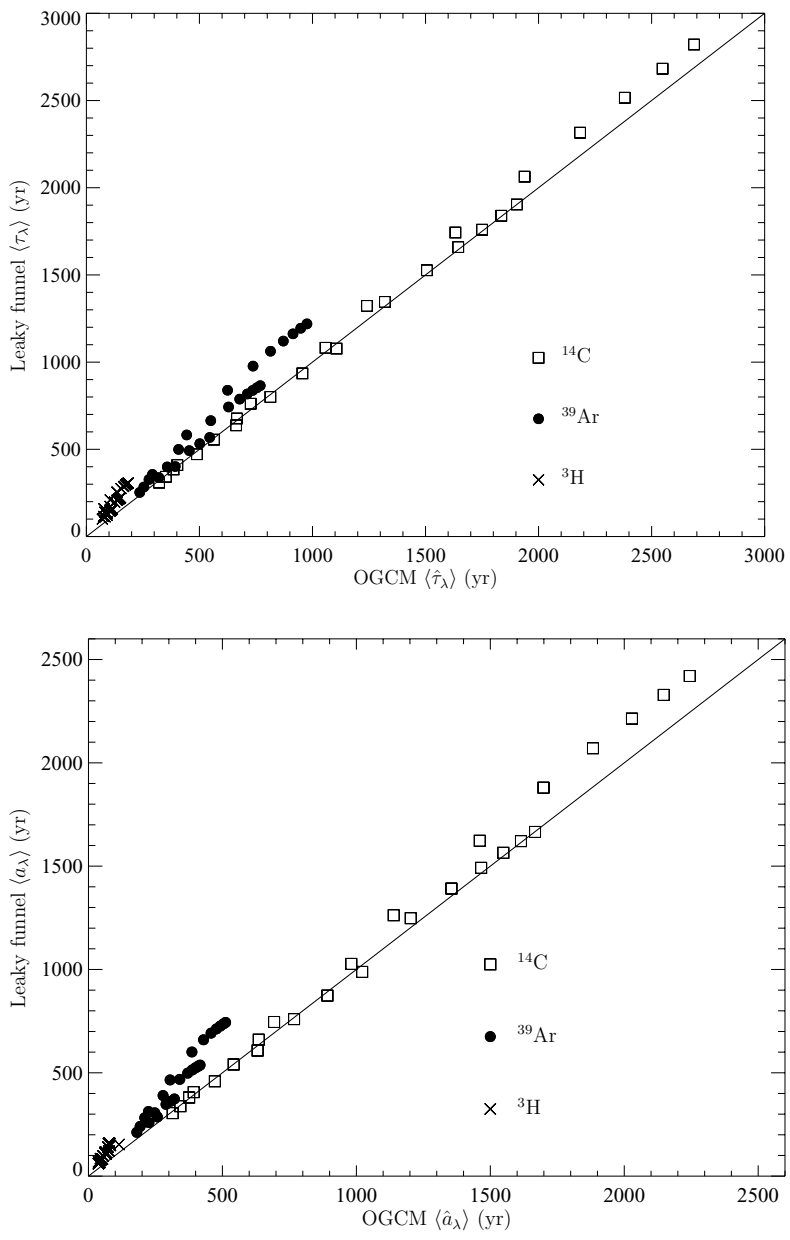

Fig. 4. Scatter plot of the predicted domain-averaged radioages (top) and radioactive tracer ages (bottom) versus those computed from the 3 -D model. The leaky funnel ages are computed by means of eqs (31)-(32) and the parameters in Table 3. The linear correlation coefficients and rms differences corresponding to the fit for each of the radioactive tracer are given in Table 4.

The agreement for the radioelement ages is excellent for ${ }^{14} \mathrm{C}$ but deteriorates as $\lambda$ increases: the leaky funnel predicted ages are systematically larger (older) than the 3-D model values (Fig. 4). The reasons thereof are to be found in the heterogeneity of the 3-D circulation and the fact that distinct water masses fill the deep ocean in the OGCM experiments. The changes in $\gamma_{i}$ and $\beta_{i}$ do not only affect the deep interior circulation but also the exchanges with the surface through changes in subduction and convection rates. In the leaky funnel representation the age is set to zero at the funnel boundary directly feeding from the ocean surface. In the 3-D OGCM the age is set to zero at the ocean surface but due to the existence of multiple pathways between the surface and the deep ocean, the water starting its journey through the deep ocean does not necessarily have a zero age. Since the 
largest values of velocity and of explicit diffusion occur in the upper ocean layers and in convection regions the initial ages of the individual water masses filling the deep ocean differ among experiments. We allow for these differences by associating an error estimate to each of the 3-D average water ages in the fitting procedure. We impose that the error increases with $\left\langle a_{w}\right\rangle_{i}$ in order to reflect the larger value of the age tagging water entering the deep ocean in the case of a slower circulation. A close look at the age distributions obtained for the $M$ experiments together with the analysis of the statistics of fit allow us to conclude that the error represents $2-3 \%$ of $\left\langle a_{w}\right\rangle_{i}$. The estimates of the parameters are not sensitive to the percentage assigned to this error but may change by a few percent for different uncertainty formulations. However, these changes do not impact significantly the order of magnitude of the derived scales presented in the next section. We also examined the robustness of the estimates by using a different procedure. The built-in IDL function CURVEFIT (Research Systems Inc., 1999) based on a gradient-expansion algorithm resulted in parameters values very close to those obtained with the Levenberg-Marquardt algorithm (relative differences of 0.1 and $0.6 \%$ for $A_{0}$ and $P e$, respectively).

The systematic bias of the age of radioactive tracers is explained by the differences in pathways and transit time towards the deep ocean. It is well known (Jenkins, 1987; Khatiwala et al., 2001; Delhez et al., 2003) that mixing processes create a bias towards younger ages and that this bias increases with increasing mixing or with increasing radioactive decay constant. The larger mixing, of both explicit and numerical types, experienced by the radioactive tracers before reaching the deep ocean results in lower ages in the 3-D experiments. As expected the discrepancy increases with $\lambda$ and results for ${ }^{3} \mathrm{H}$ are of a poorer quality than those obtained for tracers having a slower decay rate (Fig. 4).

In a sensitivity test we assumed that numerical diffusion does not contribute to the age distributions in the 3-D OGCM. In that case, the purely advective age scales $A_{0}$ decreases to $883.78 \mathrm{yr}$ while $P e^{E}$ increases to 7.33. Under this hypothesis the lack of contribution from $P e^{N}$ in the denominator of (30) is compensated for by an increase in $P e^{E}$ and a decrease in $A_{0}$. When numerical diffusion is neglected, the rms differences between the leaky funnel and the OGCM radioactive tracer ages increase while those for water ages do not change. Again this is due to the larger sensitivity of radioactive tracer ages to mixing. This sensitivity test illustrates the role played by numerical diffusion in coarse grid OGCMs (Oschlies, 2000; Doney et al., 2004).

The leaky funnel and 3-D models also generally agree for the volume distribution of water ages. In the leaky funnel this distribution is given by:

$\phi\left(a_{w}\right)=\frac{e^{-a_{w} /\left\langle a_{w}\right\rangle}}{\left\langle a_{w}\right\rangle}$,

where $\phi\left(a_{w}\right) \delta a_{w}$ represents the fraction of the volume occupied by water with ages comprised in the interval $\left[a_{w}, a_{w}+\delta a_{w}\right]$ (see Appendix A for a derivation). This volume fraction decreases



Fig. 5. Volume density distribution of water age for the standard case $\left(\gamma_{i}=1\right.$ and $\left.\beta_{i}=1\right)$. The dashed curve represents the distribution for the leaky funnel (eq. 34) with parameters from Table 3 . The volumes from the 3-D experiment (solid) were grouped into $75 \mathrm{yr}$ bins.

exponentially as age increases (Fig. 5). The solid line in the same figure is the distribution of the 3-D model ages. In order to derive the latter curve, we computed the volume density corresponding to $75 \mathrm{yr}$ age intervals. There is a general agreement between both distributions. The local maximum in the 3-D model curve at large ages apparently results from a recirculation cell in the deep Pacific Ocean.

Such a close match between a very simple 1-D model and a complex 3-D ocean circulation model with its multiple ventilation pathways is unexpected. We devoted many efforts to find hidden dependencies among the parameters as well as to examine every aspects of our method. However we did not find any bias in our reasoning. Hence we assume that the close correspondence is not a methodological artefact.

\section{Discussion}

In what follows we examine the physical relevance of the values in Table 3 and derive the characteristic circulation scales. From the leaky funnel we obtain a timescale and a dimensionless parameter related to the circulation in the global ocean: $A_{0}=\frac{L}{U}=1010.36 \mathrm{yr}$ and $P e=\frac{U L}{K}=3.34$ (Table 3). $A_{0}$ is a measure of the average ventilation time in the absence of diffusion processes. From (21) it is easily seen that $\left\langle a_{w}\right\rangle \leq A_{0}$ for any $P e$. Hence $A_{0}$ provides an upper limit of the actual ventilation timescale.

Most observational estimates of deep ocean ventilation timescales actually measure the turnover (or flushing) times as they are usually based on the knowledge of a reservoir size and its budget (e.g. Broecker and Peng, 1982; Stuiver et al., 1983; Broecker et al., 1999b). However, the mean age and the flushing 
time represent conceptually different timescales which, in most cases, have different values (Bolin and Rodhe, 1973).

In the leaky funnel, $A_{0}$ measures the turnover time of water while the turnover time of a radioactive tracer is $\theta\left(C_{\lambda}\right)=$ $A_{0} /\left(A_{0} \lambda+1\right)$ (see Appendix B for a full derivation). Hence the turnover time for radiocarbon in the leaky funnel is $\theta\left({ }^{14} \mathrm{C}\right) \simeq 901$ $\operatorname{yr}\left(\lambda=1.2 \times 10^{-4} \mathrm{yr}^{-1}\right)$. Broecker et al. (1999b) obtained a value of $850 \mathrm{yr}$ for the turnover time of the deep ocean based on the production rate of new deep water. ${ }^{2}$ Several authors estimated the flushing time of the deep ocean from radiocarbon inventories to be comprised between 500 and $1000 \mathrm{yr}$ (Stuiver et al., 1983; Broecker and Peng, 1982). Given the many uncertainties these values compare rather favourably with the timescales derived from the leaky funnel.

For a reservoir at steady-state, a turnover time larger than the domain-averaged water age indicates a situation in which the source and sink areas are away from each other (Bolin and Rodhe, 1973). This corresponds well with the deep sea reservoir whose sources are located in polar areas and sinks distributed among the main ocean basins.

There are not many global estimates of oceanic Pe. Based on literature sources it seems that the characteristic Peclet number for global horizontal ocean circulation is comprised between 1 and 10. Takeoka (1991) used a 2-D model to reproduce the vertical distribution of observed radiocarbon ages in the Pacific Ocean; he obtained the best agreement for $P e=5$. Larger values are usually assumed close to the surface ocean. For example, Colin de Verdière (1993) derives a Peclet number of 10 from typical surface velocities and motion length scale.

Scaling arguments for the steady overturning circulation in a simplified basin point to a link between the horizontal circulation and the vertical diffusion (Bryan, 1987; Huang, 1999). Mass balance and a vertical advective-diffusive balance of the density lead to the following scaling laws

$U_{h} L_{v} \sim W L_{h} \quad$ and $\quad L_{v} \sim K_{v} / W$,

where $L_{h}, L_{v}, U_{h}, W$ and $K_{v}$ are appropriate scales for the horizontal and vertical motion, the horizontal and vertical velocities and the vertical diffusion, respectively. From (35) we obtain

$A_{0}=\frac{L}{U} \equiv \frac{L_{h}}{U_{h}} \sim \frac{L_{v}^{2}}{K_{v}}$.

With $A_{0}$ from Table 3 and $L_{v} \sim 2 \times 10^{3} \mathrm{~m}$ we obtain $K_{v} \sim$ $1.3 \times 10^{-4} \mathrm{~m}^{2} \mathrm{~s}^{-1}$. This diffusivity level agrees well with several estimates of subthermocline mixing (Munk, 1966; Munk and Wunsch, 1998; Toole and McDougall, 2001).

$A_{0}$ and $P e$ are based on three characteristic scales of the flow: $L, U$ and $K$. As the model does not provide a third relationship linking these three scales, one scale needs to be imposed in order to derive the two others. The velocity scale $U$ is estimated as the

\footnotetext{
${ }^{2}$ Assuming that the deep ocean occupies $60 \%$ of the total ocean volume and that the rate of deep water formation is $30 \mathrm{~Sv}$.
}

average velocity amplitude over the deep ocean. The deep ocean in the 3-D model may be defined to be the water that is at least $1000 \mathrm{~m}$ below the surface (Fig. 2). For depths larger than $1 \mathrm{~km}$ the mean horizontal velocity $U$ in the 3 -D model is $\sim 3 \times$ $10^{-3} \mathrm{~m} \mathrm{~s}^{-1}$. With this value, the spatial scale and the diffusivity are easily derived, that is, $L=9.6 \times 10^{4} \mathrm{~km}$ and $K=8.6 \times$ $10^{4} \mathrm{~m}^{2} \mathrm{~s}^{-1}$.

$L$ is the e-folding length of the leaky funnel section but it also represents the average distance travelled by water parcels in the leaky funnel model (Appendix A). The length scale derived from the leaky funnel representation seems to be coherent with the large-scale tracer and nutrient distributions in the ocean (Broecker, 1991).

The scaling for $K$ may be examined in the light of the study of Okubo (1971) who provided upper and lower bounds for the horizontal diffusivity as a function of the length scale of motion in the sea. The upper and lower bounds for diffusivity proposed by Okubo (1971) are represented by the black lines in Fig. 6. From that figure we may derive the length scales associated with the diffusivity obtained from the leaky funnel model (dotted lines in Fig. 6). These length scales are in the interval $2.0 \times 10^{3}-$ $2.1 \times 10^{4} \mathrm{~km}$. Such length scales are comparable to those of basin-scales processes. It must be stressed that these characteristic lengths are not of the same nature as the length scale $L$, the former being related to the largest scales of motion in the World Ocean while the latter represents the mean distance travelled by water parcels in the deep ocean. This is why the orders of magnitude of these length scales are different.

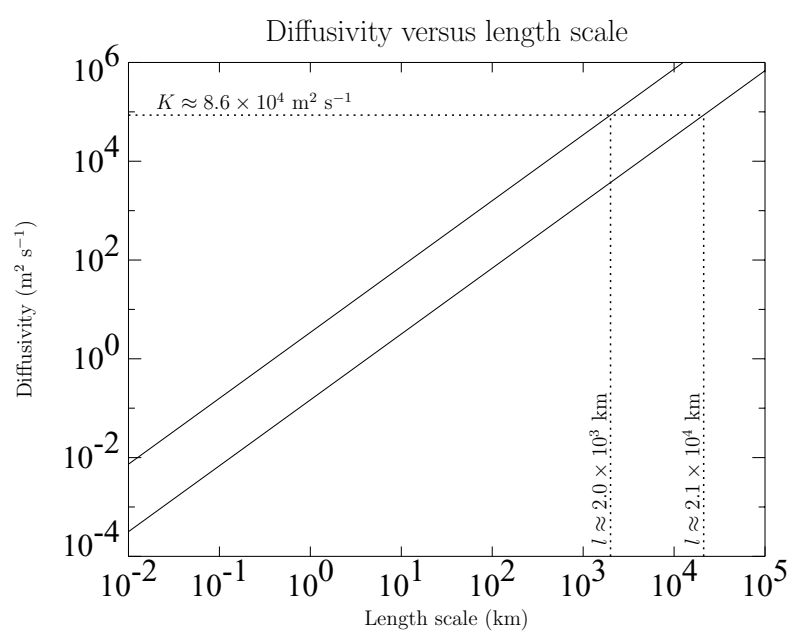

Fig. 6. Relationship between horizontal diffusivity and length scale in the ocean (from Okubo, 1971). On these logarithmic scales the two solid lines have a slope of $4 / 3$ and represent the upper and lower bounds for the diffusivity associated with a particular length scale. As indicated by the dotted lines, the value of the diffusivity $K$ associated with the leaky funnel corresponds to length scales between $2.0 \times 10^{3}$ and $2.1 \times 10^{4} \mathrm{~km}$. 


\section{Conclusions and perspectives}

The leaky funnel model presented in this study appears to provide an adequate description of some transport properties of a 3-D model of the large-scale ocean circulation. The scales suggested by this conceptual model have a clear physical meaning and are consistent with our current perception of the World Ocean circulation.

Several questions are raised in this work. The excellent agreement between the ages predicted by the 1-D funnel model and those obtained in the 3-D simulations appears robust. The volume distribution of water age of the leaky funnel and that of the OGCM reference state, which is not a direct product of the sensitivity analysis, compare favourably. Further, the parameters suggested from the leaky funnel model, that is $A_{0}$ and $P e$, for water ages, are clearly independent. We do not have any satisfactory explanation for such a close agreement, which was unexpected at first. Presently, we are examining the reasons leading to this behaviour and are working on the possible interpretations.

The scales $A_{0}$ and $P e$ derived from the leaky funnel are based on OGCM domain-averaged water ages, the OGCM being calibrated against other field data or climatology (T, S. . ). It should be stressed that these scales reflect the OGCM internal transport and the relative role of advection and diffusion in reproducing the observed tracer distributions. The method we adopted has some questionable aspects since the flow fields considered here are not dynamically consistent, but this method seems relevant as it allows the measure of the scales of the ventilation time with respect to velocity and/or diffusivity changes.

The derived Peclet number, $P e \sim 3$, appears at first to be small. This value is in line with the results of a recent analysis of the large-scale ocean ventilation (Holzer and Primeau, 2006) which points to a somewhat diffusive large-scale ocean transport. However, we could also question the transport in our OGCM as models from this generation are known to be quite diffusive (Oschlies, 2000; Doney et al., 2004).

The leaky funnel also has limitations due to its simple representation of the 'return' flow. The agreement would also need to be tested against 3-D model with more detailed or 'realistic' vertical mixing as this process is highly heterogeneous (Polzin et al., 1997; St. Laurent et al., 2001).

The simple physical analogue provided by the leaky funnel model could be a useful tool in model intercomparison studies. Extracting the scales $A_{0}$ and $P e$ by means of the method presented herein could help in evidencing the large-scale circulation characteristics in OGCMs. Indeed, similar distributions of mean water ages could potentially be obtained from OGCMs with different dynamics. More (or less) advection together with less (or more) diffusion would then result in a larger (smaller) $A_{0}$ together with a smaller (larger) $P e$. Preliminary tests with another OGCM (the Hamburg LSG OGCM, Maier-Reimer et al., 1993), seem promising and the derived values are fully consis- tent with the observed differences between the respective 3-D tracer distributions.

\section{Acknowledgments}

The authors thank Jean-Michel Campin and Jean-Marie Beckers for fruitful discussions and an anonymous reviewer for very constructive comments which helped much in improving the manuscript. A. Mouchet thanks the Belgian Federal Science Policy (BELSPO) for support through the ASTER project (SD/CS/01A). Eric Deleersnijder is a Research Associate with the Belgian National Fund for Scientific Research (FNRS); he is indebted to Professor Tom W.N. Haine for useful discussions during the first stage of the design of the leaky funnel model.

\section{Appendix A: Volume distribution and average trajectory length}

The volume distribution function of water age is defined in such a way that $\phi\left(a_{w}\right) \delta a_{w}$ represents the fraction of volume in which the water age lies in the interval $\left[a_{w}, a_{w}+\delta a_{w}\right]$. In the leaky funnel, this volume fraction is

$\phi\left(a_{w}\right) \delta a_{w}=\frac{S(x) \delta x}{L S_{0}}$

with $S(x)=S_{0} \exp (-x / L)$. Expression (21) may be transformed to

$a_{w}(x)=\frac{x}{L}\left\langle a_{w}\right\rangle$

implying that $\delta a_{w}=\left(\left\langle a_{w}\right\rangle / L\right) \delta x$. Combining all of the above equations leads to

$\phi\left(a_{w}\right)=\frac{a_{w}}{\left\langle a_{w}\right\rangle} e^{-a_{w} /\left\langle a_{w}\right\rangle}$

A fraction $(S(x)-S(x+\Delta x)) / S_{0}$ of the fluid parcels leaves the funnel in the interval $[x, x+\Delta x]$ after having travelled a distance that tends towards $x$ as $\Delta x / L \rightarrow 0$. Since

$\frac{S(x)-S(x+\Delta x)}{S_{0}} \rightarrow \frac{-1}{S_{0}} \frac{\mathrm{d} S}{\mathrm{~d} x} \Delta x$, for $\frac{\Delta x}{L} \rightarrow 0$

the mean trajectory length is then given by the e-folding scale of the section,

$\int_{0}^{\infty} x \frac{-1}{S_{0}} \frac{\mathrm{d} S}{\mathrm{~d} x} \mathrm{~d} x=\frac{1}{L} \int_{0}^{\infty} x \mathrm{e}^{-x / L} \mathrm{~d} x=L$

\section{Appendix B: Turnover time}

The turnover time is defined as the ratio of the content of a reservoir to the sum of its sinks (Bolin and Rodhe, 1973). At steady-state the sinks must balance the sources. The source term is provided by the inflow of new material at $x=0$. This flux is 
given by

$F_{\lambda}(0)=S_{0}\left\{U C_{\lambda}(0)-K\left[\frac{\partial C_{\lambda}(x)}{\partial x}\right]_{\text {at } x=0}\right\}$

With the help of (16) and the definition of $U^{\prime}\left(U^{\prime}=U+K / L\right)$ this flux is

$$
\begin{aligned}
F_{\lambda}(0) & =S_{0}\left[U+\frac{U^{\prime}}{2}\left(\sqrt{1+\frac{4}{J e^{\prime}}}-1\right)\right] \\
& =\frac{S_{0} K}{L}\left[\frac{U^{\prime} L}{2 K}\left(\sqrt{1+\frac{4}{J e^{\prime}}}+1\right)-1\right]
\end{aligned}
$$

The inventory of a tracer with concentration $C_{\lambda}$ in the leaky funnel is

$$
\begin{aligned}
Q_{\lambda} & =\int_{0}^{\infty} S(x) C_{\lambda}(x) \mathrm{d} x \\
& =S_{0} \int_{0}^{\infty} \exp \left[-\frac{x}{L}-\frac{U^{\prime} x}{2 K}\left(\sqrt{1+\frac{4}{J e^{\prime}}}-1\right)\right] \mathrm{d} x \\
& =\frac{S_{0} L}{1+\frac{U^{\prime} L}{2 K}\left(\sqrt{1+\frac{4}{J e^{\prime}}}-1\right)}
\end{aligned}
$$

Hence

$\theta\left(C_{\lambda}\right)=\frac{Q_{\lambda}}{F_{\lambda}(0)}=\frac{L}{U} \frac{1}{\lambda(L / U)+1}=\frac{A_{0}}{\lambda A_{0}+1}$.

The turnover time for water or a passive constituent $(\lambda=0)$ is then given by $A_{0}$. This timescale provides an upper limit for the turnovertime of any radioactive tracer.

\section{References}

Archer, D., Martin, P., Milovich, J., Brovkin, V., Plattner, G.-K. and co-authors. 2003. Model sensitivity in the effect of Antarctic sea ice and stratification on atmospheric $\mathrm{pCO}_{2}$. Palaeoceanography 18, 1012, doi: 10.1029/2002PA000760.

Bolin, B. and Rodhe, H. 1973. A note on the concepts of age distribution and transit time in natural reservoirs. Tellus 25, 58-62.

Broecker, W. S. 1991. The great ocean conveyor. Oceanography 4, 79 89.

Broecker, W. S. and Peng, T.-H. 1982. Tracers in the Sea. Lamont Doherty Geological Observatory, Columbia University, New York, $690 \mathrm{p}$.

Broecker, W. S. and Peng, T.-H. 2000. Comparison of ${ }^{39} \mathrm{Ar}$ and ${ }^{14} \mathrm{C}$ ages for waters in the deep ocean. Nucl. Instrum. Methods Phys. Res. Sect. B 172, 473-478.

Broecker, W. S., Lynch-Stieglitz, J., Archer, D., Hoffmann, M., MaireReimer, E. and co-authors. 1999a. How strong is the Harvardton-Bear constraint? Glob. Biogeochem. Cycle 13, 817-820.

Broecker, W. S., Sutherland, S. and Peng, T. 1999b. A possible 20thcentury slowdown of Southern Ocean deep water formation. Science 286, 1132-1135.

Broecker, W. S., Peacock, S., Walker, S., Weiss, R., Fahrbach, E. and co-authors. 1998. How much deep water is formed in the Southern Ocean? J. Geophys. Res. 103, 15833-15844.
Bryan, F. 1987. Parameter sensitivity of primitive equation OGCMs. $J$. Phys. Oceanogr. 17, 970-985.

Campin, J.-M., Fichefet, T. and Duplessy, J.-C. 1999. Problems with using radiocarbon to infer ocean ventilation rates for past and present climates. Earth Planet. Sci. Lett. 165, 17-24.

Campin, J.-M. and Goosse, H. 1999. Parameterization of density-driven downsloping flow for a coarse-resolution ocean model in z-coordinate. Tellus 51, 412-430.

Colin de Verdière, A. 1993. On the oceanic thermohaline circulation. In: Modelling the Ocean-Climate Interactions (eds J. Willebrand and D. L. T. Anderson), Springer Verlag, Heidelberg, 151-183.

Craig, H. 1971. The deep metabolism: oxygen consumption in abyssal ocean water. J. Geophys. Res. 76, 5078-5086.

Deleersnijder, E. and Campin, J.-M. 1995. On the computation of the barotropic mode of a free-surface world ocean model. Ann. Geophys. 13, 675-688.

Deleersnijder, E., Campin, J.-M. and Delhez, E. 2001. The concept of age in marine modelling. I. Theory and preliminary model results. $J$. Mar. Syst. 28, 229-267.

Deleersnijder, E., Mouchet, A., Delhez, E. and Beckers, J.-M. 2002. On the transient behaviour of water ages in the world ocean. Math. Comput. Model. 36, 121-127.

Delhez, E., Campin, J.-M., Hirst, A. C. and Deleersnijder, E. 1999. Toward a general theory of the age in ocean modelling. Ocean Model. 1, 17-27.

Delhez, E., Deleersnijder, E., Mouchet, A. and Beckers, J.-M. 2003. A note on the age of radioactive tracers. J. Mar. Syst. 38, $277-$ 286.

Doney, S. C. and Jenkins, W. J. 1994. Ventilation of the deep western boundary current and abyssal western North Atlantic: estimates from tritium and ${ }^{3} \mathrm{He}$ distributions. J. Phys. Oceanogr. 24, 638-659.

Doney, S. C., Lindsay, K., Caldeira, K., Campin, J.-M., Drange, H. and co-authors. 2004. Evaluating global ocean carbon models: The importance of realistic physics. Glob. Biogeochem. Cycle 18, GB3017, doi:10.1029/2003GB00215.

Dutay, J.-C., Jean-Baptiste, P., Campin, J.-M., Ishida, A., Maier-Reimer, E. and co-authors. 2004. Evaluation of OCMIP-2 ocean models' deep circulation with mantle helium-3. J. Mar. Syst. 48, 15-36, doi:10.1016/j.jmarsys.2003.05.010.

England, M. H. 1995. The age of water and ventilation timescales in a global ocean model. J. Phys. Oceanogr. 25, 2756-2777.

England, M. H. and Maier-Reimer, E. 2001. Using chemical tracers to assess ocean models. Rev. Geophys. 39, 29-70.

Gruber, N. 1998. Anthropogenic $\mathrm{CO}_{2}$ in the Atlantic Ocean. Glob. Biogeochem. Cycle 12, 165-191.

Haidvogel, D. and Bryan, F. 1992. Ocean general circulation modeling. In: Climate System Modeling (ed. K. E. Trenberth), Cambridge University Press, USA, chap. 11, 371-412.

Haine, T. W. N. and Hall, T. M. 2002. A generalized transport theory: water-mass composition and age. J. Phys. Oceanogr. 32, 19321946.

Hall, T., Haine, T. and Waugh, D. 2002. Inferring the concentration of anthropogenic carbon in the ocean from tracers. Glob. Biogeochem. Cycle 16, 1131-273, doi:10.1029/2001GB001835.

Heinze, C., Maier-Reimer, E. and Winn, K. 1991. Glacial $\mathrm{pCO}_{2}$ reduction by the world ocean: experiments with the Hamburg carbon cycle model. Palaeoceanography 6, 395-430. 
Hirst, A. C. 1999. Determination of water component age in ocean models: application to the fate of north atlantic deep water. Ocean Model. 1, 81-94.

Holzer, M. and Hall, T. M. 2000. Transit-time and tracer-age distributions in geophysical flows. J. Atmos. Sci. 57, 3539-3558.

Holzer, M. and Primeau, F. W. 2006. The diffusive ocean conveyor. Geophys. Res. Lett. 33, L14, 618, doi:10.1029/2006GL026232.

Huang, R. X. 1999. Mixing and energetics of the oceanic thermohaline circulation. J. Phys. Oceanogr. 29, 727-746.

Jenkins, W. J. 1987. ${ }^{3} \mathrm{H}$ and ${ }^{3} \mathrm{He}$ in the Beta Triangle: observations of gyre ventilation and oxygen utilization rates. J. Phys. Oceanogr. 17, 763-783.

Jenkins, W. J. 1998. Studying subtropical thermocline ventilation and circulation using tritium and ${ }^{3}$ He. J. Geophys. Res. 103, 15 817-15 831.

Khatiwala, S., Visbeck, M. and Schlosser, P. 2001. Age tracers in an ocean GCM. Deep-Sea Res. 48, 1423-1441.

Kunze, E., Firing, E., Hummon, J. M., Chereskin, T. K. and Thurnherr, A. M. 2006. Global abyssal mixing inferred from lowered ADCP shear and CTD strain profiles. J. Phys. Oceanogr. 36, 1553-1576 (Corrigendum pp 2350-2352).

Maier-Reimer, E. 1993. Geochemical cycles in an ocean general circulation model. Preindustrial tracer distributions. Glob. Biogeochem. Cycle 7, 645-677.

Maier-Reimer, E., Mikolajewicz, U. and Hasselmann, K. 1993. Mean circulation of the Hamburg LSG OGCM and its sensitivity to the thermohaline surface forcing. J. Phys. Oceanogr. 23, 731-757.

Marotzke, J. 1991. Influence of convective adjustment on the stability of the thermohaline circulation. J. Phys. Oceanogr. 21, 903-907.

Munk, W. 1966. Abyssal recipes. Deep-Sea Res. 13, 707-730.

Munk, W. and Wunsch, C. 1998. Abyssal recipes II: energetics of tidal and wind mixing. Deep-Sea Res. 45, 1977-2010.

Neu, J. L. and Plumb, R. A. 1999. Age of air in a "leaky pipe" model of stratospheric transport. J. Geophys. Res. 104, 19243-19255.

Okubo, A. 1971. Oceanic diffusion diagrams. Deep-Sea Res. 18, 789802.

Oschlies, A. 2000. Equatorial nutrient trapping in biogeochemical ocean models: the role of advection numerics. Glob. Biogeochem. Cycle 14, 655-667.

Pacanowski, R. C. and Philander, S. G. H. 1981. Parameterization of vertical mixing in numerical models of tropical oceans. J. Phys. Oceanogr. 11, 1443-1451.

Plumb, R. A. 1996. A "tropical pipe" model of atmospheric transport. $J$. Geophys. Res. 101, 3957-3972.

Polzin, K. L., Toole, J. M., Ledwell, J. R. and Schmitt, R. W. 1997. Spatial variability of turbulent mixing in the Abyssal Ocean. Science 276, 93-96.
Press, W., Flannery, B., Teukolsky, S. and Vetterling, W. 1988. Numerical Recipes. Cambridge University Press, Cambridge.

Research Systems Inc. 1999. IDL software, version 5.3.

Roache, P. 1972. On articial viscosity. J. Comput. Phys. 10, 169-184.

Robbins, P., Price, J., Owens, W. and Jenkins, W. 2000. The importance of lateral diffusion for the ventilation of the lower thermocline in the subtropical north atlantic. J. Phys. Oceanogr. 30, 67-89.

St. Laurent, L. et al 2001. Buoyancy forcing by turbulence above rough topography in the abyssal Brazil Basin. J. Phys. Oceanogr. 31, 34763495 .

St. Laurent, L. and Simmons, H. 2006. Estimates of power consumed by mixing in the ocean interior. J. Climate 19, 4877-4890.

Stommel, H. 1958. The abyssal circulation. Deep-Sea Res. 5, 8082.

Stommel, H. and Arons, A. 1960. On the abyssal circulation of the world ocean-I. Stationary planetary flow patterns on a sphere. Deep-Sea Res. 6, 140-154.

Stuiver, M., Quay, P. and Östlund, H. G. 1983. Abyssal water carbon-14 distribution and the age of the world oceans. Science 219, 849-851.

Takeoka, H. 1991. Effects of the deep ocean circulation on the reservoir characteristics of the ocean. J. Oceanogr. Soc. Japan 47, 27-32.

Talley, L. D. 1999. Some aspects of ocean heat transport by the shallow, intermediate and deep overturning circulations. In: Mechanisms of Global Climate Change at Millenial Time Scales, Geophys. Monogr. Ser., Volume 112 (eds P. U. Clark, R. S. Webb and L. D. Keigwin), AGU, Washington, DC, 1-22.

Thiele, G. and Sarmiento, J. 1990. Tracer dating and ocean ventilation. J. Geophys. Res. 95, 9377-9391.

Thomas, H. and Ittekkot, V. 2001. Determination of anthropogenic $\mathrm{CO}_{2}$ in the North Atlantic Ocean using water mass ages and $\mathrm{CO}_{2}$ equilibrium chemistry. J. Mar. Syst. 27, 325-336.

Toggweiler, J. R., Dixon, K. and Bryan, K. 1989. Simulations of radiocarbon in a coarse-resolution world ocean model. 1. Steady state prebomb distributions. J. Geophys. Res. 94, 8217-8242.

Toole, J. and McDougall, T. 2001. Mixing and stirring in the ocean interior. In: Ocean Circulation and Climate. Observing and Modelling the Global Ocean, Chap. 5.2 (eds G. Siedler, J. Church and J. Gould), Academic Press, San Diego, USA, 337-356.

Warren, B. 1981. Deep circulation of the world ocean. In: Evolution of Physical Oceanography (eds B. Warren and C. Wunsch), MIT Press, Cambridge, MA, 6-41.

Waugh, D. W. and Hall, T. M. 2005. Propagation of tracer signals in boundary currents. J. Phys. Oceanogr. 35, 1538-1552.

Wunsch, C. 2002. Oceanic age and transient tracers: analytical and numerical solutions. J. Geophys. Res. 107, 3048, doi:10.1029/2001JC000797. 